(Lyons et al., 1967), this could well be due to the emphysema.

Nevertheless, the pathogenesis and detailed pathological features of the fine type of coal workers' pneumoconiosis may not be identical with those showing the coarser changes. It is already known, for instance, that many cases of simple pneumoconiosis with coarse nodulation have been shown to be rheumatoid in origin and thus have characteristic pathological features of their own (Caplan, 1953). Certainly the parenchyma adjacent to the nodules is more extensively involved in the former cases than in those with the coarser changes, and it may be that this difference is not solely due to the emphysema (compare Figs. 6 and 7). This aspect, which is very important, will be the focus of further study of the material, as will the findings relating to bronchitis.

We are indebted to Dr. J. Watkins-Pitchford, Chief Medical Adviser, Department of Health and Social Security, for permission to use the Panel material; to those senior medical officers who read the $x$-ray films; and to Miss C. Squance, Cardiff P.M.P., for valuable secretarial assistance.

\section{REFERENCES}

Caplan, A. (1953). Thorax, 8, 29.

Cochrane, A. L. Moore, F., and Thomas, J. (1961). Tubercle, 42, 64.

Cotes, J. E. (1965). Lung Function, p. 350. Oxford, Blackwell Scien-

Duguid, J. B., and Lambert, M. W. (1964). Fournal of Pathology and Bacteriology, 88, 389.

Fletcher, C. M. (1968). In Form and Function in the Human Lung, ed. G. Cumming and L. B. Hunt, p. 37. Edinburgh, Livingstone.

Gooding, C. G. (1946). Lancet, 2, 891.

Gough, J. (1940). Fournal of Pathology and Bacteriology, 51, 277.

Gough, J., James, R. W. L., and Wentworth, J. E. (1949). Fournal of the Faculty of Radiologists, 1, 28.

Gough, J., and Wentworth, J. E. (1960). In Recent Advances in Pathology, ed. C. V. Harrison, 7th edn. London, Churchill.

Heard, B. E., and Izukawa, T. (1964). Fournal of Pathology and Bacteriology, 88, 423 .

Heppleston, A. G. (1947). Fournal of Pathology and Bacteriology, 59, 453. Heppleston, A. G. (1954). fournal of Pathology and Bacteriology, 67,

Lyons, J. P., Clarke, W. G., Hall, A. M., and Cotes, J. E. (1967). British Medical fournal, 4, 772 .

Medical Research Council (1966). British Medical fournal, 1, 101.

Reid, Lynne (1967). Pathology of Emphysema, p. 47. Lloyd-Luke, London.

Ryder, R. C., Thurlbeck, W. M., and Gough, J. (1969). American Review of Respiratory Diseases, $99,354$.

Snider, G. L., Brodie, J. S., and Doctor, L. (1962). American Review of Respiratory Diseases, 85, 666.

\title{
Tissue Matching and Early Rejection of Cadaveric-Donor Renal Allografts: The Importance of Unidentified Donor Antigens
}

J. H. STEWART,* M.B., M.R.C.P., M.R.A.C.P. ; KERRIN M. COOK, † B.sC. ; A. M. SHARP, † M.sC.

JILL M. JOHNSTON, $\dagger$ B.SC. ; A. G. R. SHEIL, $\ddagger$ M.S., F.R.C.S., F.R.A.C.S. ; D. JEREMY, $\$ M.B., B.S., M.R.A.C.P. HELEN BASHIR,\| M.B., D.C.P., M.C.P.A.

British Medical fournal, 1970, 3, 487-490

\begin{abstract}
Ummary: Tissue typing has been reviewed in a series $\checkmark$ of 100 technically succ ssful cadaveric-donor kidney grafts. The criterion if transplant failure was immunological rejection causing total loss of function within three months of operation.

No significant correlation was observed between matching grade and graft failure due to early acute rejection. This is attributed to the failure to detect at least one "LA" or "4" antigen (as defined in our laboratory), representing a potential incompatibility, in $89 \%$ of the grafts, and in the remaining $11 \%$ to the lack of an available recipient with identical "LA" and "4" typing. Undetected antigens on the donor are usually incompatible, and probably these incompatibilities unfavourably influence early graft survival.

If the results of cadaveric-donor renal transplantation are to equal those of transplantation from well-matched living related donors it will be necessary to type with sera which can recognize individually all HL-A antigens, including those not yet identified, and to create an international pool of over 1,000 potential recipients.
\end{abstract}

\section{Introduction}

Since grafts exchanged between two siblings with an identical HI-A genotype are subject to a degree of rejection little greater than that occurring in transplants between identical twins (Stickel et al., 1967), there can be little doubt that HL-

* Renal Physician, Medical Research Department, Sydney Hospital, Sydney 2000, Australia.

t Scientific Officer, Tissue Typing Laboratory, New South Wales Red Cross Blood Transfusion Service, Sydney 2000, Australia.

¥ Associate Professor of Surgery, University of Sydney, Camperdown 2050, Australia.

Chairman, Division of Renal Diseases, Prince Henry Hospital, Little Bay 2035, Australia.

|| Assistant Director, N.S.W. Red Cross Blood Transfusion Service and Medical Officer-in-Charge, Tissue Typing Laboratory, Sydney 2000, Australia.
A or a closely adjacent locus carries the most important genetic determinants for histocompatibility in man. That $\mathbf{H L}-\mathbf{A}$ is indeed the major locus is confirmed by the demonstration that preimmunization of a recipient with cells carrying foreign HL-A antigens will cause accelerated rejection of a subsequent graft from a donor with these antigens (Dausset et al., 1965; van Rood et al., 1965; Kissmeyer-Nielsen et al., 1966; Terasaki et al., 1968; Patel and Terasaki, 1969; Stewart et al., 1969), that purified preparations of soluble HL-A antigens can stimulate lymphocytes in culture (Viza et al., 1968), and that donor-specific HL-A antibodies appear in patients at the time of rejection of renal allografts (Manzler, 1968; Morris et al., 1969). When transplants are exchanged between unrelated donor-recipient pairs, however, it is not always possible to show a correlation between $\mathbf{H L}-\mathbf{A}$ matching and early acceptance or rejection of renal allografts (Patel et al., 1968).

Tissue matching has been used in Sydney for recipient selection in a city-wide collaborative programme of cadavericdonor renal transplantation since 1967 (Sheil et al., 1969). One-sixth of the grafts in this series underwent early acute rejection, but these rejections could not have been predicted from the tissue typing data obtained. This report analyses the incomplete nature of $\mathrm{HL}-\mathrm{A}$ typing as at present carried out in a clinical laboratory.

\section{Methods}

The analysis is based on 100 technically successful renal allotransplantations carried out between March 1968 and September 1969, and followed for at least three months after operation. Another 16 transplantations carried out in the same period have been excluded because of inadequate typing of the donor (four cases) or graft failure or death during the first two months due to causes other than rejection. Standard methods were used for clinical procedures and for immunosuppression (Sheil et al., 1968; Tracy et al., 1969). The diagnosis of rejection was confirmed by demonstration of 
the characteristic lesions in a biopsy or nephrectomy specimen of the graft (Porter et al., 1963; Kincaid-Smith, 1967).

HI-A typing of donor and recipient was performed by a microdroplet lymphocyte cytotoxicity test developed from those described by Walford et al. (1964) and Terasaki et al. (1967). Throughout this analysis the concept of an HL-A locus with at least two discrete subloci, designated "LA" and "4" (Kissmeyer-Nielsen et al., 1968), has been used. Reliable sera detecting five allelic antigens of the "LA" sublocus, HL$A 1,2,3,9$, and 11 (S Ly2) and five of the "4" sublocus, $\mathrm{HL}$ A5, 7, 8, 12 (S Lyl), and S Ly5 were used. S Ly5 has yet to be identified with any previously described antigen. One additional allele at the " 4 " sublocus, designated " $4 c$ " ( $R^{*}$ of Kissmeyer-Nielsen), could be recognized in subjects whose cells were positive with the sera Fuller and Hamilton, but negative with the HL-A5 sera, VR 2708 and To/01/02 (Sharp et al., 1970). The gene frequencies of these alleles in the Australian population, as calculated by Sharp, are given in Table III. Results of typing with multispecific sera, anti-4a and anti-4b sera, or sera which detect antigens not yet proved to be alleles of one or other of the two recognized HI-A subloci, though used by our laboratory for clinical purposes, have been excluded from consideration in this paper.

Each individual should carry two antigenic determinants, one paternal and one maternal, at each sublocus, and for complete typing of the two subloci four antigens must be detected. Since undetected antigens are more likely to be incompatible than compatible (see below), the number of potential incompatibilities in any donor-recipient pair has been calculated by adding to the demonstrated incompatibilities the number of donor antigens not detected.

\section{Clinical Results}

Eighteen of the 100 allografts ceased to function as a result of acute irreversible rejection during the first three months after operation. There were no instances of "hyperacute" rejection-that is, rejection occurring immediately or within 24 hours of operation-and only four of the rejections were apparent during the first week after operation. Only six rejections occurred later than three months after operation, and these have not been included in this analysis.

The occurrence of early acute rejection could not be related to the sex or parity of the recipient, to the use of local $x$ irradiation of the graft for immunosuppression, or to the presence of cytotoxic antibodies in the recipient at the time of transplantation (5 rejections, 29 cases; $17 \%$ ). A report on the results of a controlled clinical trial of antilymphocyte globulin on these patients is being prepared. The basic conclusions reached in the present paper are not affected by the improved survival rate of grafts in those patients treated with antilymphocyte globulin.

There was no relationship between the incidence of early acute rejection and the matching grade, as determined by the number of incompatible (donor-positive, recipient-negative) antigens demonstrated (Table I) or potentially present (Table II). Separate examination of the data for each of the antigens failed to show any significant association between early acute rejection and incompatibility of any one antigen when considered alone (Table III). The series was too small to determine whether or not certain incompatibilities, when present together, had an adverse effect on early graft survival.

Ninety-eight of the donor-recipient pairs were typed for all five recognized alleles of the "LA" sublocus, but in only 48 were both antigens of the donor identified. With respect to the "4" sublocus, both donor antigens were identified in no more than 22 of the allografts. Complete typing for both subloci with identification and matching of all four donor antigens was achieved in as few as 11 of the donor-recipient pairs, and in all at least one incompatibility was found. In the other 89 transplantations, which included 17 of the 18 rejected grafts, there was a demonstrable incompatibility in 64 , and the remaining 25 each had at least one potential incompatibility at one or other sublocus.

When these typing results were related to acute rejection (Table IV) it could be seen that ensuring that there was no incompatibility at the "LA" sublocus alone did not reduce significantly the rate of early failure. The numbers were too small to determine whether or not compatibility at the "4" sublocus alone or at both the "LA" and the "4" sub-loci would avoid acute rejection. TABLE I.-Relationship of Early Acute Rejection of Cadaveric-Donor Renal
Allografts to Incompatibility of " $L A$ " and " 4 " Antigens

\begin{tabular}{|c|c|c|c|c|c|c|}
\hline \multicolumn{4}{|c|}{ No. of Incompatibilities Detected } & \multirow[t]{2}{*}{ No. of Grafts } & \multicolumn{2}{|c|}{$\begin{array}{l}\text { Early Acute } \\
\text { Rejections }\end{array}$} \\
\hline & & & & & No. & $\%$ \\
\hline $\begin{array}{ll}\mathbf{0} & \ldots \\
1 & \ldots \\
2 & \ldots \\
3 & \ldots \\
4 & \ldots\end{array}$ & $\begin{array}{l}. . \\
\because . \\
\because .\end{array}$ & $\begin{array}{l}. \\
\because \\
\because\end{array}$ & $\begin{array}{l}\because \\
\because \\
\because\end{array}$ & $\begin{array}{r}25 \\
35 \\
25 \\
14 \\
1\end{array}$ & $\begin{array}{l}5 \\
7 \\
3 \\
3 \\
0\end{array}$ & $\begin{array}{r}20 \\
20 \\
12 \\
21 \\
0\end{array}$ \\
\hline Total & .. & .. & .. & 100 & 18 & \\
\hline
\end{tabular}

'TABLE II.-Relationship of Early Acute Rejection of Cadaveric-Donor Renal "Allografts to Number of Potentially Incompatible Donor Antigens at the

\begin{tabular}{|c|c|c|c|c|c|}
\hline \multirow{2}{*}{\multicolumn{2}{|c|}{ No. of Potential Incompatibilities* }} & & \multirow[t]{2}{*}{ No. of Grafts } & \multicolumn{2}{|c|}{$\begin{array}{l}\text { Early Acure } \\
\text { Rejections }\end{array}$} \\
\hline & & & & No. & $\%$ \\
\hline $\begin{array}{ll}0 & . \\
1 & \because \\
2 & \because \\
3 & . \\
4 & . .\end{array}$ & $\begin{array}{ll}\because & . \\
\because & \because \\
\because & \because \\
\because & \because\end{array}$ & $\begin{array}{l}\because \\
\because \\
\because \\
.\end{array}$ & $\begin{array}{r}0 \\
7 \\
28 \\
37 \\
28\end{array}$ & $\begin{array}{l}\overline{2} \\
6 \\
4 \\
6\end{array}$ & $\begin{array}{l}\overline{29} \\
21 \\
11 \\
21\end{array}$ \\
\hline
\end{tabular}

-Demonstrated incompatibilities plus undetected donor antigens.

TABLE III.-Relationship of Early Acute Rejection of Cadaveric-Donor Renal Allografts to Incompatibility of Individual HL-A Antigens

\begin{tabular}{|c|c|c|c|c|c|c|c|c|}
\hline \multirow{2}{*}{\multicolumn{3}{|c|}{ Antigen }} & \multirow{2}{*}{$\begin{array}{c}\text { Gene } \\
\text { Frequency }\end{array}$} & \multicolumn{2}{|c|}{ Incompatible Grafts } & \multicolumn{2}{|c|}{ Compatible Grafts } & \multirow[b]{2}{*}{$x_{2}$} \\
\hline & & & & No. & $\%$ Rejected & No. & $\%$ Rejected & \\
\hline $\begin{array}{l}\text { HL-A1 } \\
\text { HL-A2 } \\
\text { HL-A3 } \\
\text { HILA9 } \\
\text { HL-A11 }\end{array}$ & $\begin{array}{l}\ldots \\
\cdots \\
\cdots \\
\cdots\end{array}$ & $\begin{array}{l}\ldots \\
\ldots \\
\ldots \\
\ldots\end{array}$ & $\begin{array}{l}0.20 \\
0.30 \\
0.14 \\
0.09 \\
0.05\end{array}$ & $\begin{array}{r}8 \\
13 \\
19 \\
22 \\
9\end{array}$ & $\begin{array}{l}25 \\
15 \\
11 \\
18 \\
33\end{array}$ & $\begin{array}{l}92 \\
87 \\
81 \\
77 \\
90\end{array}$ & $\begin{array}{l}17 \\
18 \\
20 \\
18 \\
17\end{array}$ & $\begin{array}{l}0.3 \\
= \\
0.06\end{array}$ \\
\hline $\begin{array}{l}4 c " \\
\text { HL-A5 } \\
\text { HL-A7 } \\
\text { HL-A8 } \\
\text { HL-A12 } \\
\text { S Ly5 }\end{array}$ & $\begin{array}{l}. \\
\cdots \\
\cdots \\
\cdots\end{array}$ & $\begin{array}{l}\ldots \\
\ldots \\
\cdots \\
\ldots\end{array}$ & $\begin{array}{l}0.07 \\
0.07 \\
0.17 \\
0.11 \\
0.15 \\
0.03\end{array}$ & $\begin{array}{r}5 \\
14 \\
17 \\
3 \\
14 \\
2\end{array}$ & $\begin{array}{r}20 \\
36 \\
12 \\
0 \\
7 \\
0\end{array}$ & $\begin{array}{l}82 \\
77 \\
83 \\
75 \\
86 \\
36\end{array}$ & $\begin{array}{r}16 \\
14 \\
19 \\
19 \\
20 \\
8\end{array}$ & $\begin{array}{l}0.06 \\
3.8 \\
= \\
=\end{array}$ \\
\hline
\end{tabular}

TABLE IV.-Relationship of Early Acute Rejection of Cadaveric-Donor Renal Allografts to Incompatibility at One or Other $H L-A$ Sublocus

\begin{tabular}{|c|c|c|c|c|c|c|c|c|c|}
\hline \multicolumn{8}{|c|}{ No. of Incompatible Antigens } & \multirow{2}{*}{$\begin{array}{c}\text { Rejected } \\
3 \\
4 \\
3\end{array}$} & \multirow{2}{*}{$\begin{array}{c}\text { Survived } \\
10 \\
20 \\
8\end{array}$} \\
\hline “LA" sub $\begin{array}{r}0 \\
1 \\
2\end{array}$ & $\begin{array}{l}\text { us: } \\
\ldots \\
\ldots\end{array}$ & $\begin{array}{l}\cdots \\
\cdots \\
\therefore\end{array}$ & $\begin{array}{l}\cdots \\
\cdots\end{array}$ & $\begin{array}{l}\cdots \\
\cdots\end{array}$ & $\begin{array}{l}\cdots \\
\cdots\end{array}$ & $\begin{array}{l}\cdots \\
\cdots\end{array}$ & $\begin{array}{l}\cdots \\
\cdots\end{array}$ & & \\
\hline \multicolumn{2}{|c|}{ Total* } & . & . & . & $\ldots$ & . & . & 10 & 38 \\
\hline “4" subloc $\begin{array}{r}0 \\
1 \\
2\end{array}$ & $\begin{array}{l}: \\
. \\
\because \\
\ldots\end{array}$ & $\begin{array}{l}\cdots \\
\cdots\end{array}$ & $\begin{array}{l}\ldots \\
\therefore\end{array}$ & $\begin{array}{l}\ldots \\
\cdots \\
\cdots\end{array}$ & $\begin{array}{l}\ldots \\
\cdots\end{array}$ & $\begin{array}{l}\cdots \\
\cdots \\
\cdots\end{array}$ & $\begin{array}{l}\cdots \\
\cdots\end{array}$ & $\begin{array}{l}0 \\
1 \\
1\end{array}$ & $\begin{array}{r}1 \\
13 \\
6\end{array}$ \\
\hline & & $\ldots$ & . & $\ldots$ & $\ldots$ & .. & $\ldots$ & 2 & 20 \\
\hline
\end{tabular}

*Excluded are grafts in which one or both donor antigens were not identified, or else not typed in the recipient.

\section{Theoretical Analysis of Typing Data}

The validity of certain of the findings in this series is subject to confirmation by simple mathematical analysis. Thus it can be calculated that, with the panel of sera used, typing of the "LA" and "4" subloci will be incomplete in seven out of every eight donors, 
and more than half of the undetected antigens will be incompatible. Furthermore, it can be shown that to ensure the availability of two compatible recipients for most donors, the size of the recipient pool must exceed 1,000 .

Both antigens of a sublocus would be identified when the subject is heterozygous for two of the recognized alleles. The frequency with which this would occur is given by the formula

$$
\left.\underset{1}{\mathbf{n}} \mathbf{p}_{\mathbf{i}}\right)^{2}-\sum_{1}^{\mathbf{n}}\left(\mathbf{p}_{\mathbf{i}}{ }^{2}\right)
$$

(derived from the Hardy-Weinberg law) where $p_{1}$ is the gene frequency of an allele at that sublocus, and $n$ is the number of recognized alleles. The frequency with which complete typing would be achieved for both subloci can be computed from the formula.

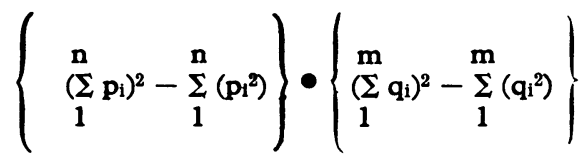

where $q_{i}$ is the gene frequency of an antigen at the other sublocus and $m$ is the number of recognized alleles. Therefore both "LA" antigens should be identified in $45 \%$ of donors, both " 4 " antigens in $29 \%$ of donors, and all four antigens in $13 \%$ of donors. The frequencies observed in the present small series were similar to the expected frequencies, the smaller percentage of donors in whom both "4" antigens were detected being attributable to the incomplete typing of some of the earlier donors for $4 \mathrm{c}, \mathrm{HL}-\mathrm{A} 5$, HL-A8, and S Ly5 (Table III).

Failure to detect one donor antigen may be due to the homozygous state of a known antigen, and this would not constitute an additional incompatibility. Twenty-seven per cent. of undetected "LA" antigens and $8.5 \%$ of undetected "4" antigens can be accounted for in this way. Alternatively, the undetected antigen may be one of the unrecognized alleles in either the homozygous or heterozygous state. The number of these antigens which will be compatible is given by $\sum_{i}^{n}\left(A_{i}{ }^{2}\right)$ where $A_{i}$ is the antigenic frequency of an unknown allele. The antigenic frequency is related to the gene frequency according to the formula

$$
A=2 p-p^{2}
$$

(from $\mathrm{p}=1-\sqrt{1}-\mathrm{A}$; Kissmeyer-Nielsen et al., 1968).

It follows that the fewer the number of unrecognized alleles the higher will be the proportion of undetected antigens which are compatible. Since the newly discovered alleles have been those with lower gene frequencies, it seems probable that several infrequently occurring alleles rather than one or two alleles with high gene frequencies are yet to be discovered at each sublocus. This conclusion is supported by data published by Walford et al. (1969). If at each sublocus there are four undiscovered alleles each with roughly equal gene frequencies, then between $25 \%$ and $35 \%$ of the undetected antigens would be compatible. Thus, assuming that there are no recessive or inactive $\mathrm{HL}-\mathrm{A}$ determinants, a point of view taken by Walford (1969), most of the undetected antigens will be incompatible.

If the antigens of the two HL-A subloci were randomly associated the frequency with which a recipient will be found to match a completely typed donor would be equal to

where $i, j=1,2 \ldots \ldots n$

$$
R\left(2 p_{i} p_{j} .2 q_{1} q_{j}\right)
$$

$\mathbf{n}=$ number of alleles at each sublocus

$p_{i}$ or $p_{j}$ represents the gene frequency of an allele of the "LA" sublocus

$\mathrm{q}_{\mathrm{i}}$ or $\mathrm{q}_{\mathrm{j}}$ represents the gene frequency of an allele of the "4" sublocus

$\mathbf{R}$ represents the proportion of $\mathrm{ABO}$ compatible recipients in the population

The most common phenotype (HL-A1, HL-A2, HL-A7, HL-A12), if found in a blood group $O$ donor, would be compatible for about - 6 per 1,000 of the recipient population, and the least common phenotype (HL-A9, HL-A11, HL-A5, S Ly5), if group $O$, for about 4 per 100,000 . In fact, the antigens are not randomly associated, for HL-A1 and 8, HL-A2 and 12, HL-A3 and 7, and HL-A11 and " $4 c$ " tend to occur together (Sharp et al., 1970). This increases the frequencies of the common phenotypes, so that, for example, HL-A1, HL-A8, HL-A2, HL-A12 would occur in about $2 \%$ of potential recipients instead of the calculated 4 per 1,000. Nevertheless, the common phenotypes, for which a recipient pool of rather less than 1,000 would suffice, comprise no more than $10-20 \%$ of the population. For the remainder the patient pool would need to exceed 1,000 to ensure the availability of two compatible recipients.

\section{Discussion}

The ultimate aim of tissue typing for cadaveric-donor transplantation must be to achieve excellent acceptance of the graft by ensuring complete HL-A compatibility. This requires identification and matching of all four donor antigenic determinants of the "LA" and "4" subloci and of both determinants of any further subloci which may be discovered. For identification, a panel composed of antisera with limited and known specificity and detecting each of the individual alleles, is necessary, and, for matching, an enlarged recipient pool numbering more than 1,000 .

Throughout this study certain assumptions have been madein particular, that all $\mathrm{HL}-\mathrm{A}$ antigens have a roughly equal capacity to induce graft rejection and that incompatibilty even for a single antigen should be avoided. Previously published evidence concerning the relative strengths of the known HL-A antigens has been summarized by Walford (1969), whose conclusions support the validity of the first assumption. And in the present series, whereas no one of the recognized antigens, when considered individually, was clearly associated with early rejection, it can be inferred from the rejection of five grafts in which no identifiable antigen was incompatible that at least some of the unrecognized antigens have the capacity to induce acute rejection.

There are several possible explanations for our failure to show a correlation between the number of incompatibilities, either demonstrated or potential, and early acute rejection: (1) that early rejection is as much determined by the immunological reactivity of the recipient as by the antigenic disparity present; (2) that a single incompatibility is as important as several; (3) that there are additional HL-A subloci besides the two described; (4) that certain combinations of antigens act synergistically, or else, conversely, the presence of one antigen in the recipient may induce a degree of tolerance to a closely related antigen in the graft; and (5) that non-HL-A antigens play a rather greater part in early than in late rejection.

On superficial examination the first is unlikely to be an important factor, since of the five second grafts given to recipients who had rejected their first only one underwent early acute rejection. On the other hand, recipients of cadaver grafts almost invariably have been exposed to foreign $\mathrm{HL}-\mathrm{A}$ antigens, if not by pregnancy then by blood transfusion during the period of preoperative dialysis. Some of these recipients may have become sensitized to one or more but not necessarily all foreign HL-A antigens, yet may not have formed a detectable titre of cytotoxic antibody. If such a recipient were given a graft carrying one of these antigens the cross match with the donor's lymphocytes might be negative, yet an acute secondary response, delayed some weeks by immunosuppressive therapy, might occur and cause rejection. Though there is no firm evidence to support this theory, it fits the clinical picture of early rejection, and might explain why this type of rejection is less easy to predict by tissue typing than is late rejection (Patel et al, 1968).

The second possibility seems to be ruled out by the knowledge that kidney grafts from HL-A identical siblings are accepted better than are parent-child grafts, in which only one-half of the antigenic determinants are matched (Singal et al., 1969), and these in turn fare better than do grafts between unrelated pairs with, on the whole, fewer than half the antigens matched. In this series there were two grafts which were rejected despite matching of three of the four "LA" and 
" 4 " antigens. In the single instance in which the fourth mismatched antigen was identified it was HL-A5.

The possibility of there being third and fourth HL-A subloci has been raised by Walford et al. (1969). If such should be the case, and the strength of their alleles proves to be comparable to those of the "LA" and "4" subloci, the results in this series could be readily explained. Moreover, unless their antigenic determinants are more strongly associated with those of other subloci than has been demonstrated for "LA" and "4" alleles (Sharp et al., 1970), it will be virtually impossible to achieve identical matching of donor and recipient.

Knowledge concerning immunological interrelationships, as distinct from genetic associations, in the HL-A system is scanty, as are data concerning the role of non-HL-A antigens other than those of the ABO system. The observation that no combination of mismatched recognized antigens was associated with early acute rejection in the present series does not rule out a synergistic action between antigens, for the number of rejected grafts was small and a significant proportion of antigens were not identified.

We believe that incompatibility of the less easily recognized HL-A antigens, and presensitization without formation of detectable cytotoxic antibodies, will prove to be major factors determining the early acute rejection of allografts from unrelated donors.

We wish to acknowledge the team-work and assistance of our colleagues at Sydney, Prince Henry, Royal Prince Alfred, and St. Vincent's Hospitals, particularly Professor G. F. Murnaghan, Dr. J. R. Johnson, Mr. J. May, Dr. J. Hayes and Mr. R. A. Lord, and Dr. G. T. Archer, Director of the New South Wales Red Cross Blood Transfusion Service.

\section{REFERENCES}

Dausset, J., Rapaport, F. T., Ivanyi, P., and Colombani, J.((1965). Series Haematologica, No. i1, p. 63.

Kincaid-Smith, P. (1967). Lancet, 2, 849.

Kissmeyer-Nielsen, F., Olsen, S., Petersen, V. P., and Fjeldborg, O. (1966). Lancet, 2, 662.

Kissmeyer-Nielsen, F., Sveigaard, A., and Hauge, M. (1968). Nature, 219, 1116.

Manzler, A. D. (1968). Transplantation, 6, 787.

Morris, P. J., Mickey, M. R., Singal, D. P., and Terasaki, P. I. (1969), British Medical fournal, $1,758$.

Patel, R., Mickey, M. R., and Terasaki, P. I. (1968). New England fournal of Medicine, 279, 501 .

Patel, R., and Terasaki, P. I. (1969). New England fournal of Medicine, 280, 735 .

Porter, K. A., et al. (1963). British Medical fournal, 2, 639.

Rood, J. J. van, et al. (1965). Series Haematologica, No. 11, p. 37.

Sharp, A. M., Cook, K. M., and Johnston, J. M. (1970). Nature. In press.

Sheil, A. G. R., et al. (1968). Medical fournal of Australia, 2, 1079.

Sheil, A. G. R., et al. (1969). Lancet, 2, 917.

Singal, D. P., Mickey, M. R., and Terasaki, P. I. (1969). Transplantation, $7,246$.

Stewart, J. H., et al. (1969). Lancet, 1, 176.

Stickel, D. L., Amos, D. B., Zmijewski, C. M., Glenn, J. F., and Robinson, R. R. (1967). Transplantation, 5, 1024 .

Terasaki, P. I., Thrasher, D. L., and Hauber, T. H. (1968). Advance in Transplantation, ed. J. Dausset, J. Hamburger, and G. Mathé, p. 225, Copenhagen, Munksgaard.

Terasaki, P. I., Vredevoe, D. L., and Mickey, M. R. (1967). Transplantation, 5,1057 .

Tracy, G. D., Annetts, D. L., Farnsworth, R. H., Jeremy, D., and Murnaghan, G. F. (1969).' Australian and New Zealand fournal of Surgery, 39, 26.

Viza, D. C., Degani, O., Dausset, J., and Davies, D. A. L. (1968). Nature, $219,704$.

Walford, R. L. (1969). Series Haematologica, 2, No. 2.

Walford, R. L., Gallagher, R., and Sjaarda, J. R. (1964). Science, 144, 868. Walford, R. L., Zeller, E., Finklestein, S., Waters, H., and Smith, G. S. (1969). Proceedings of the 12th Congress of the International Society of Blood Transfusion, Moscow.

\title{
Loss of Skeletal Calcium by Patients on Maintenance Dialysis
}

\author{
P. J. ATKINSON, ${ }^{*}$ L.R.C.P., M.R.C.S., PH.D. ; R. R. WEST, † M.A., PH.D. ; F. M. PARSONS, $\ddagger$ M.D., B.SC., F.R.C.P.ED. \\ G. W. REED, $\$ M.SC.
}

British Medical fournal, 1970, 3, 490-492

Summary: Direct radiological measurements of the min$\checkmark$ eral content of femoral bone were performed in 13 patients on maintenance dialysis. They were found to be sufficiently sensitive to be used for monitoring, and it is suggested that the technique gives more information than do calcium-balance studies.

\section{Introduction}

Maintenance dialysis reduces the severity of uraemia and prolongs the lives of patients with chronic renal failure. Nevertheless, the prevalence and the development of metabolic bone disease in these patients would suggest that there is a basic abnormality of calcium metabolism that is not yet adequately controlled by dialysis. Though Curtis et al. (1969) have shown that osteodystrophic lesions can be resolved by maintaining an optimal calcium level in dialysis fluids, a tendency for bone resorption to occur and calcium to

\footnotetext{
* Research Lecturer, Biological Research Unit, Dental School and Hospital, University of Leeds, Leeds 1 .

+ Research Assistant, Department of Medical Physics, University of Leeds, Leeds 1. Now at Department of Mathematical Statistics,
Leed University College, Cardiff.

₹ Consultant in Clinical Renal Physiology, the General Infirmary at Leeds, Leeds 1 .

Senior Lecturer, Department of Medical Physics, University of Leeds,
} Leeds 1 . be deposited in soft tissues is the more usual experience (Kleeman et al., 1969). Consequently the loss of calcium from the body, as measured in metabolic balance studies, may not give reliable information about the changes that have occurred in the bone. To resolve some of these difficulties it would be an advantage if direct measurements of bone mineral were made at regular intervals in patients treated by dialysis.

\section{Method}

This communication describes direct measurements of bone mineral that have been made on 13 patients receiving maintenance dialysis: 6 of these were treated by peritoneal dialysis and 7 by haemodialysis. Their renal function was either negligible or absent, most haemodialysis subjects having had a total nephrectomy.

The duration of the peritoneal dialysis varied between 30 and 35 hours and was repeated at weekly intervals; 2 litres of dialysis fluid was used at each hourly exchange. The calcium concentration of the dialysate was $7.2 \mathrm{mg} . / 100 \mathrm{ml}$. and the normal sodium, chloride, water ratios in plasma were maintained by the occasional addition of 1 litre of $5 \%$ dextrose in place of 1 litre of dialysis fluid (Moriarty and Parsons, 1966). The mean reduction of blood urea concentration by the dialysis was $55 \%$, and the creatinine was reduced by $36 \%$ 